\title{
Investigation of a Micro PEM Fuel Cell Pack Based on MEMS Technology
}

\author{
Tao Wang ${ }^{\mathrm{a}, \mathrm{b}}$, Xigui Zhang ${ }^{*}$,a,, Jian Zhang ${ }^{\mathrm{a}}$, Dan Zheng ${ }^{\mathrm{a}, \mathrm{c}}$, Cong Chen ${ }^{\mathrm{a}}$, Xinxin $\mathrm{Li}^{\mathrm{a}}$, \\ Chuanzheng Yang ${ }^{\mathrm{d}}$ and Baojia Xia ${ }^{\mathrm{a}}$
}

\author{
${ }^{a}$ Shanghai Institute of Microsystem and Information Technology, Chinese Academy of Sciences, Shanghai 200050, \\ China \\ ${ }^{b}$ Shanghai Institute of Space Power-Sources, Shanghai 200381, China \\ ${ }^{c}$ Shanghai Institute of Technology, Shanghai 200233, China \\ ${ }^{\mathrm{d}}$ Shanghai University, Shanghai 200444, China
}

\begin{abstract}
Investigation of a micro PEM fuel cell pack based on MEMS technology is carried out in this paper. A Novel type of Z-type anode flow field plates were applied to replace the full pin-type ones used previously and all the single cells were assembled in the same plane with a fuel distributor as their support. The total pack's volume is about $4.0 \mathrm{ml}$. Operating on dry $\mathrm{H}_{2}$ and air-breathing conditions at $20 \pm 3^{\circ} \mathrm{C}$ and $50 \pm 3 \% \mathrm{RH}$, the pack produced the peak power of $1.34 \mathrm{~W}$ and the estimated maximum power density of the pack could reach $335 \mathrm{~W} / \mathrm{L}$. Meanwhile, all the single cells had rather even performances which were based on $V-I$ and internal resistance measurement (EIS). The results suggested that the pack's performance was greatly improved compared to the previous work. The novel Z-type anode flow field leading to more even fuel distribution among each cell probably had the greatest contribution for the improvement.
\end{abstract}

Keywords: Micro PEMFC pack, MEMS fabrication, air-breathing cathode, fuel distributor, Z-type anode flow field.

\section{INTRODUCTION}

With the fast development and miniaturization of portable devices such as cellular phones, lap-top computers, digital cameras or any other mobile electronics, the micro fuel cells $(\mu \mathrm{FCs})$ with high energy density are extensively needed in today's daily life [1]. Because $\mu \mathrm{FCs}$ are widely considered to be a major candidate for the micro scaled power generation with higher energy densities than the most competitive rechargeable batteries, many researchers have taken great labor in fabrication of $\mu \mathrm{FCs}$ or its components [2-15]. However, apart from the good designs and advanced materials, miniaturizing fuel cells for micro scaled power source is actually hindered by the difficulty of reducing their physical dimensions because macro-sized fuel cell components (such as bipolar plates and fuel storage cans) are often limited by their characteristic fabrication technology constraints. Thanks to Micro-Electronic-Mechanical-System (MEMS) technology, micro-channel patterns of $\mu \mathrm{FCs}$ bipolar plates into which reactants are fed and other components (such as micro fuel reformers/processors [7, 12, 13] and micro pumps [3]) can be fabricated on a silicon wafer with high resolution and good reproducibility. It has been demonstrated that MEMS technology is one of the most promising technologies for fuel cell miniaturization and integration. However, a lot of work was focused only on using such technology for fabrication of a single cell $[2,8,9]$. In fact, for the practical

*Address correspondence to this author at the Shanghai Institute of Microsystem and Information Technology, Chinese Academy of Sciences, Shanghai 200050, China; Tel: 86-21-62511070-8813; Fax: 86-21-524139930;

E-mail: zhangxigui@mail.sim.ac.cn uses, several or even hundreds of single cells are needed to be serially grouped or integrated to offer the required voltage and power. From our knowledge, only a few of packs fabricated by MEMS technology were reported or proposed [1416]. For example, Lee et al. [14] reported a micro fuel cell pack in which a planar array of cells is serially connected in a "flip-flop" configuration. The peak power in a 4-cell silicon assembly was reported to reach $40 \mathrm{~mW} / \mathrm{cm}^{2}$ using hydrogen and oxygen as fuel and oxidizer. Yu et al. [15] fabricated miniature twin fuel cells connected in series by sandwiching two membrane-electrode assemblies between two silicon micro-machined plates. The electricity interconnection from the cathode of one cell to the anode of another cell is made in the same plane and the interconnection was fabricated by sputtering a layer of copper over a layer of gold on the top of the silicon wafer. The measured peak power density was $190.4 \mathrm{~mW} / \mathrm{cm}^{2}$ at $270 \mathrm{~mA} / \mathrm{cm}^{2}$ when operating on dry $\mathrm{H}_{2} / \mathrm{O}_{2}$ at $25^{\circ} \mathrm{C}$ and atmospheric pressure.

In this work, design, fabrication and performance characterization of a 6-cell PEMFC pack based MEMS was investigated. A novel anode flow field plates for the pack and a fuel distributor were fabricated by a classical MEMS etching and silicon-glass bonding technologies, respectively. Each cell was made by sandwiching a membrane-electrodeassembly (MEA) between two flow field plates and they were assembled in the same plane with a fuel distributor as their support. Performance and electrochemical resistance characterization of the pack were done by the linear polarization and Electrochemical Impedance Spectroscopy (EIS) under dry hydrogen and air-breathing conditions for the cathode. 


\section{EXPERIMENTAL}

\subsection{Design of the Pack}

The MEMS-based pack was made by assembling 6 single cells in the same plane with a fuel distributor as their support. The fuel distributor was fabricated by a silicon-glass bonding technology. Each cell was fabricated by sandwiching the home-made MEA between two silicon wafer-based flow field plates with an active area of $1.2 \times 1.2 \mathrm{~cm}^{2}$. Two strips of the cells were arranged with 3 cells in a row. Fuel from the hydrogen source is first flowing into the chamber of fuel distributor, then distributing to each cell through the holes formed in the Pyrex glass. A C-type channel collects exhausted gases from the 6 cells and drains them out from the outlet hole formed on the silicon wafer. The structure diagram of the 6-Cell MEMS-based PEMFC pack is schematically shown in Fig. (1).

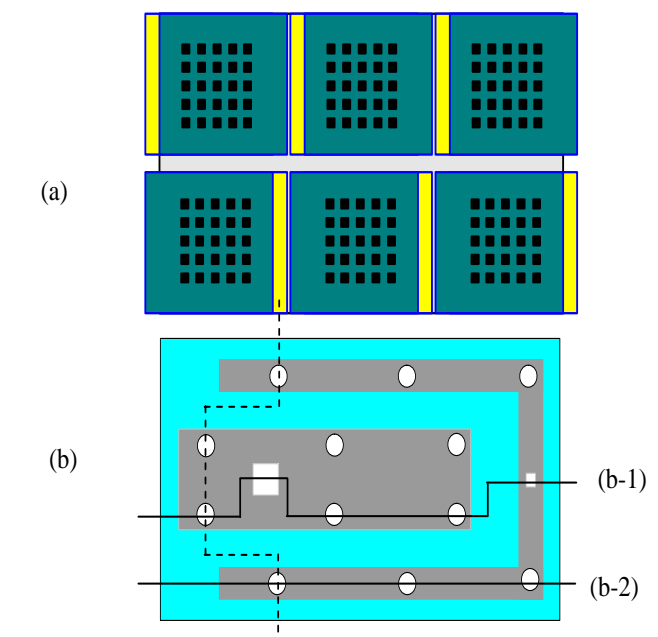

(b-3)

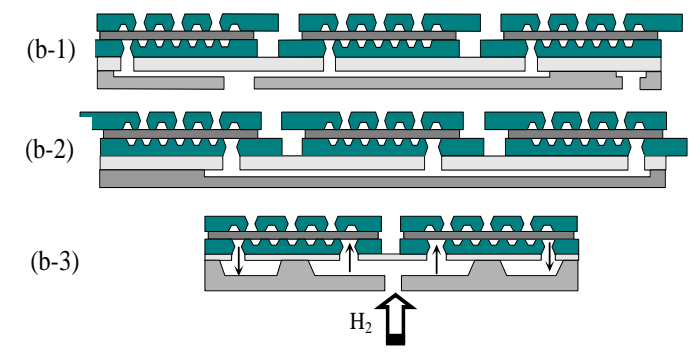

Fig. (1). The schematic structure diagram of the 6-Cell MEMSbased PEMFC pack.

\subsection{Fabrication of the Flow Field Plates and Fuel Dis- tributor by MEMS Technology}

Fig. (2) shows the fabrication sequences of Z-type anode flow field plates and air-breathing cathode. A 4 inch, $525 \pm 20 \mu \mathrm{m}$-thick $\mathrm{N}$-type $<1 \quad 0 \quad 0>$ silicon wafer with resistance ratio ranging from 1.5 to $2.5 \Omega \cdot \mathrm{cm}$ was used as the original material in this work. The fabricating processes were briefly introduced as follows: (1) Heat deposit of a silicon dioxide layer on the wafer used as a silicon etch mask; (2) Photolithography of the mask windows on the back of the wafer; (3) Heat deposit of a silicon dioxide layer again to form the different thick layers on the back of the wafer; (4) Photolithography of the mask windows on the front of the wafer; (5) Etch of the front wafer in $40 \mathrm{wt} \% \mathrm{KOH}$ solution at $50^{\circ} \mathrm{C}$ and the etching depth was controlled at $100 \mu \mathrm{m} \pm 2 \mu \mathrm{m}$; (6) Wash the wafer in BOE solution (4 portions of $40 \%$ $\mathrm{NH}_{4} \mathrm{~F}$ and 6 of $49 \%$ HF mixture solution); (7) Double sides wet the etch wafer in $\mathrm{KOH}$ solution again to form the pintype flow field patterns with two square through holes for the hydrogen plates and the through holes flow field patterns for the oxygen plates; (8) Remove the residual silicon dioxide on the surface of the wafer; (9) Heat deposit of continuous silicon dioxide layers for electrical insulation; (10) Sputtering a $\mathrm{Ti} / \mathrm{Pt} / \mathrm{Au}$ composite metal layers on the wafer surface to act as conductive layer and ensure the metal layers would bond well in contact with the silicon wafer. The thickness of $\mathrm{Ti}, \mathrm{Pt}$ and $\mathrm{Au}$ layer was controlled at $0.1 \mu \mathrm{m} .0 .3 \mu \mathrm{m}$ and $0.5 \mu \mathrm{m}$ respectively. The flow field patterns of the anode are an array of pin-type isolated 'isles' and two through pseudosquare holes for fuel in and out. The isle is about $293 \times 293 \mu \mathrm{m}^{2}$ on top and $300 \mu \mathrm{m}$ in depth. Note that two pieces of micro grooves measuring $8 \mathrm{~cm}$ were formed simultaneously (Fig. 3a). The through hole for hydrogen in is about $1.5 \times 1.5 \mathrm{~mm}^{2}$ and that for hydrogen out is about $0.5 \times 0.5 \mathrm{~mm}^{2}$ respectively. The flow field pattern of the cathode is an array of pin-type isolated through 'isles' using for air-breathing (Fig. 3b). The dimension of the flow field plate is about $1.6 \times 1.8 \mathrm{~cm}^{2}$ with active area of $1.2 \times 1.2 \mathrm{~cm}^{2}$. Note that the width and length of the two plates is not equal and about $0.2 \times 1.6 \mathrm{~cm}^{2}$ free spaces were used for spot welding between the adjacent cells. In total, ten anode flow field plates and ten cathode flow field plates were formed on the silicon wafer.

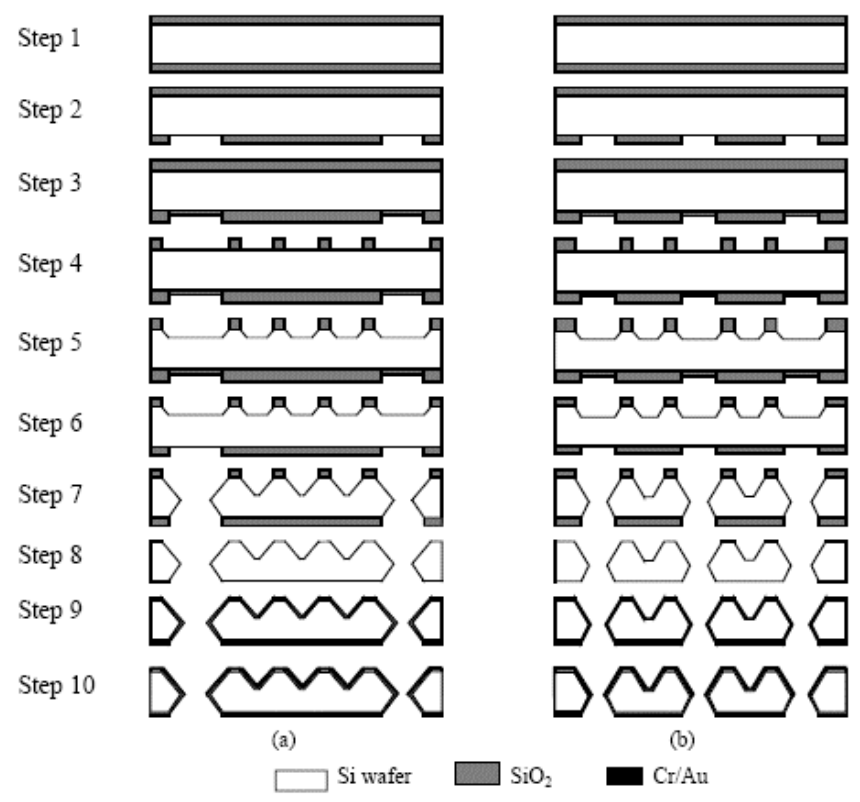

Fig. (2). The fabrication sequences of Z-type anode flow field plates and air-breathing cathode (a) anode, (b) cathode.

MEMS etching and bonding technology were applied to make the fuel distributor. First, using the similar wet etching method described above, a strip chamber with dimensions of about $43 \mathrm{~mm}$ long, $11 \mathrm{~mm}$ wide and $100 \mu \mathrm{m}$ deep was formed on the front side of another piece of silicon wafer with $350 \mu \mathrm{m}$ thickness. This chamber will act as fuel (hydrogen) distributor. A C-type channel, a fuel feed hole and a square outlet hole were fabricated at the same time. The C-type channel is about 


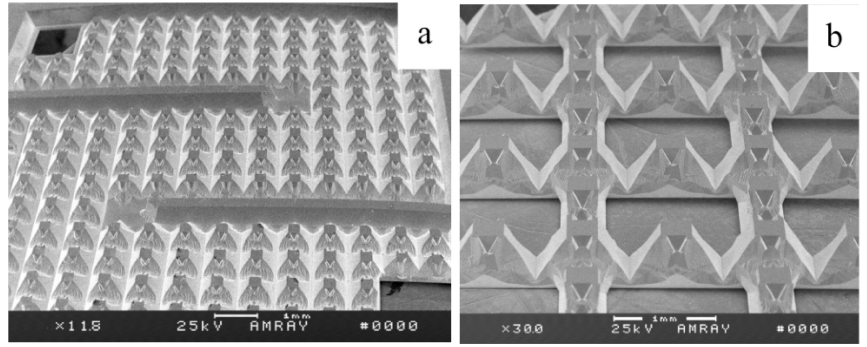

Fig. (3). The SEM pictures of the anode and cathode flow field plates fabricated. (a) anode, (b) cathode.

$3 \mathrm{~mm}$ wide and $100 \mu \mathrm{m}$ deep. The C-type channel will collect exhaust gases from the 6 cells and drain them out from the outlet hole. The fuel feed hole and outlet hole are $2.5 \mathrm{~mm}$ wide. Second, a single side is polished. A piece of Pyrex glass with $500 \mu \mathrm{m}$ thickness was ultrasonically drilled to form 12 through holes with $2 \mathrm{~mm}$ in diameter. The silicon/glass bonding was applied then in the bonding machine with $400 \mathrm{~V}$ working voltage for about 15 minutes, and the bonding temperature was controlled at about $800^{\circ} \mathrm{C}$. Note again that 6 of the 12 through holes were designed to act as the single cells' feed hole and the remains outlet holes respectively. The picture of the final bonded fuel distributor is given in Fig. (4).

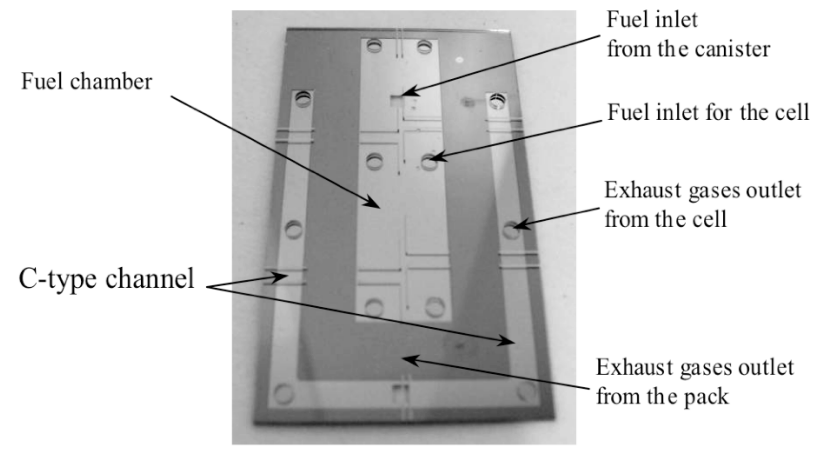

Fig. (4). The picture of the fuel distributor fabricated based on MEMS silicon-glass bonding technology.

\subsection{Assembly of the Pack}

Prior to assemble the single cells, a homemade membrane-electrode-assembly (MEA, with Pt loading $0.3 \mathrm{mg} / \mathrm{cm}^{2}$ for anode and $0.5 \mathrm{mg} / \mathrm{cm}^{2}$ for cathode respectively; Nafion112 was used as separate membrane) was cut into 6 pieces with the dimension of $1.4 \mathrm{~cm} \times 1.4 \mathrm{~cm}$. In order to prevent short-circuited, the cut MEAs were ultrasonically agitated in deionized water for several seconds to remove the residential conductive materials on the cut sides.

To assemble the single cell, a MEA was sandwiched between the anode and cathode plates and pressed for about 12 hours by an electronic spiral micrometer. A kind of Epoxy resin was used to seal the cell and act as a bonding agent between the MEA and the plates.

The assembled cells were then one by one mounted on the fuel distributor with the cathode facing up. All the void space between the cells and the glasses was filled with epoxy resin seals to guarantee no gas leakage and good sealing. Work of assembling the 6-cell pack was finally completed by spot welding the adjacent cells to make them electrically conductive. The pack is about $4.0 \mathrm{ml}$ in volume. The picture of the finally assembled pack is shown in Fig. (5).

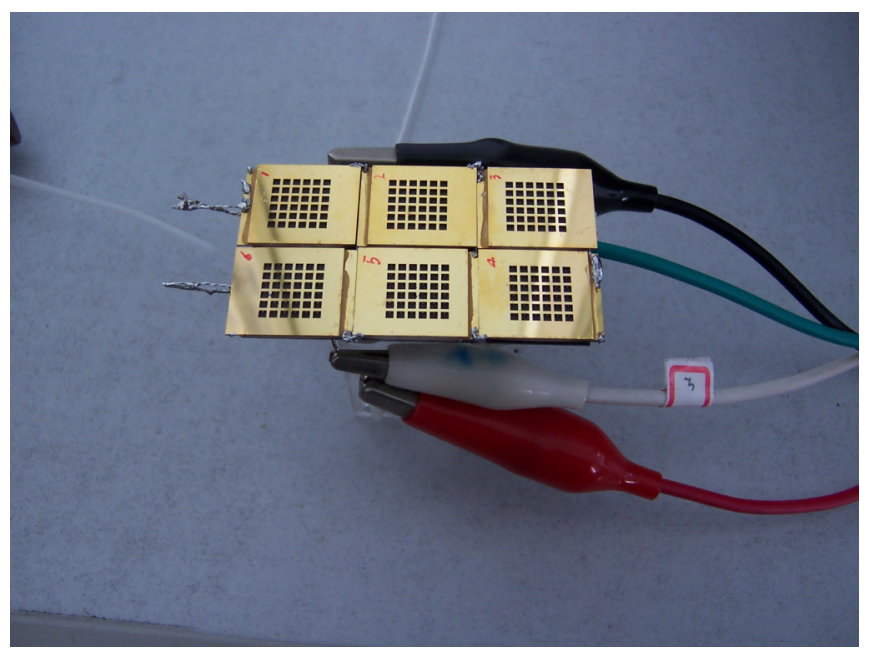

Fig. (5). The picture of the assembled pack under testing.

\subsection{Electrochemical Performance Characterization of the Pack}

Electrochemical performance characterization was carried out through the Arbin FCTs fuel cell instrument. Before collecting data, the pack was allowed to be activated for at leat one hour at a current density of $35 \mathrm{~mA} / \mathrm{cm}^{2}$. The pack was operated on dry hydrogen at atmospheric pressure and air-breathing at $20 \pm 3^{\circ} \mathrm{C}$ and $50 \pm 3 \% \mathrm{RH}$.

Impedance measurements were carried out using a Solartron SI 1287 electrochemical analyzer combined with a Solartron 1255B frequency interface and Zview 3.0 software. The instrument used in potentiostatic mode with amplitude $40 \mathrm{mV}$ over a frequency range from $0.1 \mathrm{~Hz}$ to $100,000 \mathrm{~Hz}$, covered with 10 points per decade. Nyquist plot in our impedance measurement exhibited a typical semicircle behavior. The left point of intersection with $x$ axis corresponds to ohmic resistance.

\section{RESULTS AND DISCUSSION}

Fig. (6) shows the linear polarization curve of the pack at a different hydrogen flow rates of 50,60 and $70 \mathrm{ml} / \mathrm{min}$, respectively (scan rate: $v=0.005 \mathrm{~A} / \mathrm{s}$ ). It can be seen that the shape of pack voltage versus current curve is similar as compared with the other PEMFC pack. Usually, the curve is divided into three segments by its different voltage drop rates, which correspond to different electrochemical processes [17]. The initial drop of the polarization curve at a very low current was due to the electrochemical activation process, which was caused by the sluggish kinetics of oxygen reduction at the cathode. The subsequent linear decrease of the polarization curve was due to an ohmic loss which is attributed to the ion flow through the electrolyte membrane, the electron flow through the electrode materials, flow field plates and current collector. The last drop was due to a diffusive loss caused by mass transfer difficulty of reactants, oxygen in most cases. However, it also can be seen from Fig. (6) that the pack's performance had some discrepancy with different hydrogen flow rates. When current is less than $0.1 \mathrm{~A}$, the corresponding output power had little difference; but such is not the case with further current increase, that is, at 
the region of $0.45 \sim 0.73 \mathrm{~A}$, the difference became more obvious and bigger. This could be explained by the following two negative/positive factors combined that the inner pressure of the pack and the diffusive rate of fuel for reaction went up simultaneously with the flow rate increase. So as can be expected, the moderate flow rate of $60 \mathrm{ml} / \mathrm{min}$ gave the highest output power of $1.34 \mathrm{~W}$. The peak power density of $335 \mathrm{~W} / 1$ can be calculated out based on the volume of the pack.

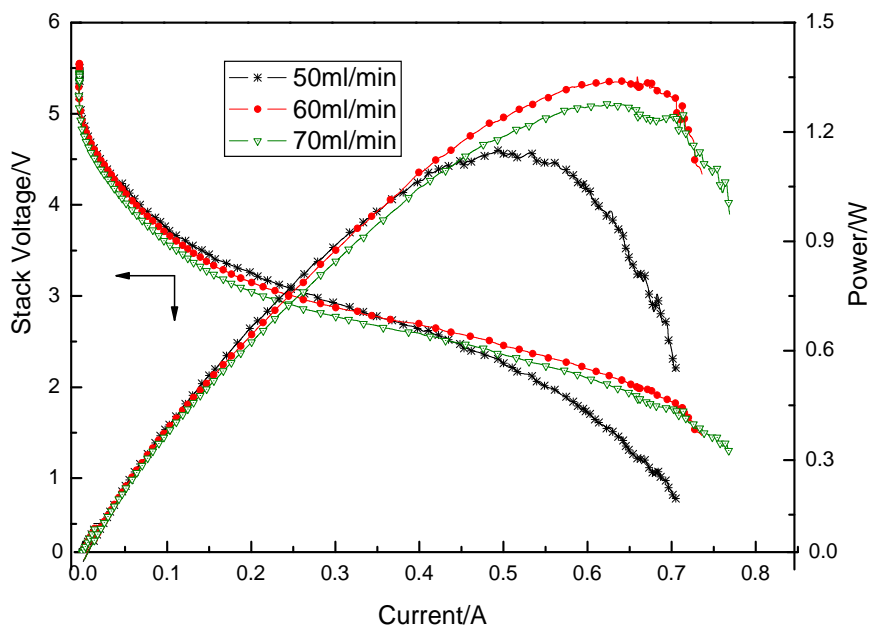

Fig. (6). The linear polarization curve of the pack with different hydrogen flow rates under conditions: $\mathrm{An} / \mathrm{Ca}=0.3 / 0.5 \mathrm{mg} \mathrm{Pt} / \mathrm{cm}^{2}$, $T_{\text {cell }}=20 \pm 3^{\circ} \mathrm{C} @ 50 \pm 3 \% \mathrm{RH}, P=$ atmospheric, and air-breathing for Cathode.

Fig. (7) shows the single cells' performance under the same conditions of Fig. (6). It is evident that all the 6 cells had a similar performance which is attributed to the even fuel distribution among each cells benefiting from the novel structure design of the pack. Table 1 list out internal resistances and peak power of the 6 cells. Also, it can be seen that they were evenly distributed.

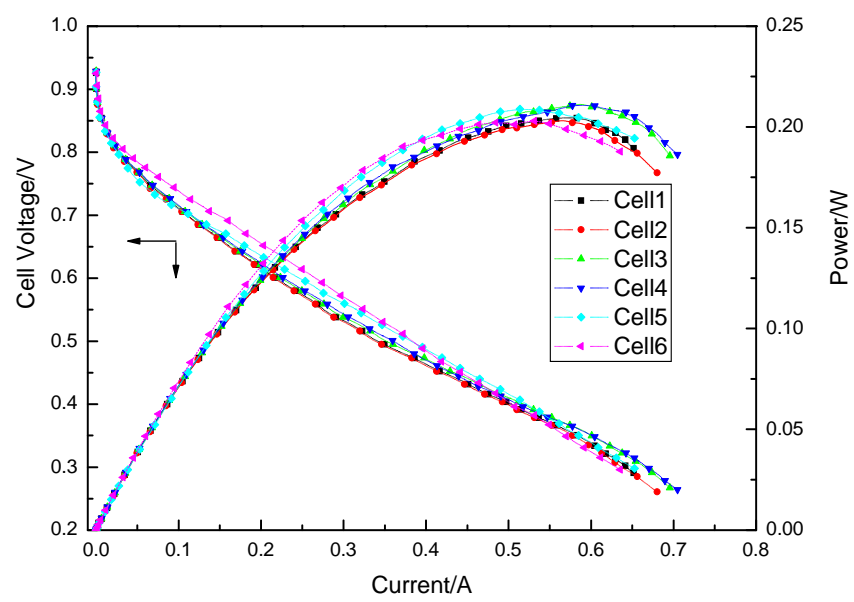

Fig. (7). The linear polarization curve of the pack with different hydrogen flow rates under conditions: $\mathrm{An} / \mathrm{Ca}=0.3 / 0.5 \mathrm{mg} \mathrm{Pt} / \mathrm{cm}^{2}$, $T_{\text {cell }}=20 \pm 3^{\circ} \mathrm{C} @ 50 \pm 3 \% \mathrm{RH}, P=$ atmospheric, and air-breathing for Cathode

Performance improvement of the sack using the novel Ztype anode flow field plates was schematically shown in Fig. (8b). Compared with the full pin-type flow field of anode we
Table 1. Internal Resistance and Peak Power of the Single Cells

\begin{tabular}{|c||c|c|c|c|c|c|}
\hline \multicolumn{1}{|c||}{ Factor } & \multicolumn{5}{c|}{ Calculated Value } \\
\hline \hline Resistance, $\boldsymbol{\Omega}$ & 0.51 & 0.51 & 0.49 & 0.50 & 0.50 & 0.51 \\
\hline Peak power, $\mathbf{W}$ & 205 & 204 & 212 & 210 & 209 & 203 \\
\hline
\end{tabular}

previously designed (see Fig. 8a), the novel type flow field can make fuel flow forcedly along Z-type road. This could mean that the fuel can reach the corner of the cells to the greatest extent, while the red circle marked place in Fig. (8a) probably not. Under the similar conditions of operation, the pack's output peak power had about $49 \%$ enhancement when the novel Z-type anode flow field plates were used to assemble the pack. More even fuel distribution among each cell probably had the greatest contribution for the improvement. Further work is to confirm the consequence and to investigate other detailed information such as heat and water management.

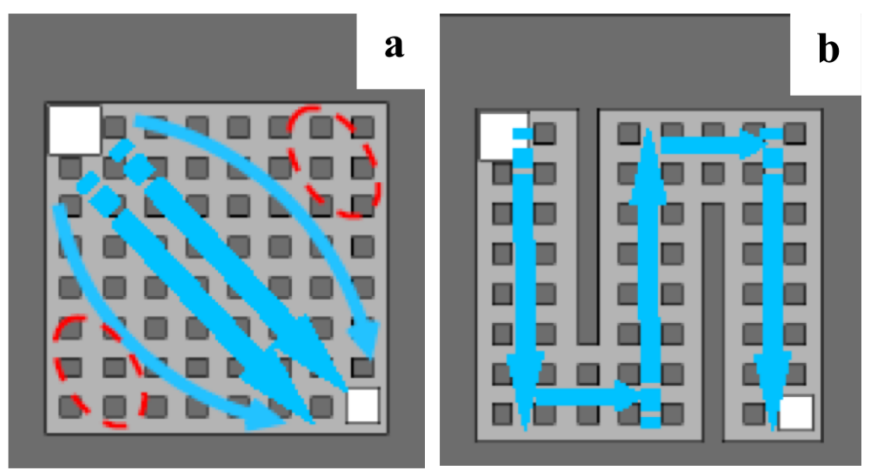

Fig. (8). The schematic diagram of fuel flow road in Z-type and full pin-type anode flow field plates (a) full pin-typed, (b) Z-typed.

\section{CONCLUSIONS}

Investigation of a micro PEM fuel cell pack with volume of $4.0 \mathrm{ml}$ based on MEMS technology was presented. The pack based on MEMS technology had a novel structure. A novel type of Z-type anode flow field plates were applied to replace the full pin-type ones used previously and all the single cells were assembled in the same plane with a fuel distributor as their support. Operating on dry $\mathrm{H}_{2}$ and airbreathing conditions at $20 \pm 3^{\circ} \mathrm{C}$ and $50 \pm 3 \% \mathrm{RH}$, the pack produced the peak power of $1.34 \mathrm{~W}$ and the estimated maximum power density of the pack could reach $335 \mathrm{~W} / \mathrm{L}$ when the pack's volume of $4.0 \mathrm{ml}$ was considered. Meanwhile, all the single cells in the pack perform well even based on $V-I$ and internal resistance measurement (EIS). The results suggested that the pack's performance was greatly improved. The novel flow field leading to more even fuel distribution among each cell probably had the greatest contribution for the improvement.

\section{ACKNOWLEDGEMENTS}

The authors gratefully acknowledge the partial financial support from Chinese Hi-tech Research and Development Program (863) under grant no. 2006AA04Z342 and National Natural Foundation of China under grant no. 20773157, 
respectively. The authors would also like to acknowledge the following members for their contributions during the preparation of this paper: Mr. Jian Yan, Mr. Jia Li, Mr. Haohan Liu, Miss Ling Zhu, Miss Yuxia Li. Special thanks to Mrs. Yuwan Lou from SIMIT for her valuable discussion and comments.

\section{REFERENCES}

[1] Yamazaki, Y. Application of MEMS technology to micro fuel cells. Electrochim. Acta, 2004, 50, 663-66.

[2] Lu, G.Q.; Wang, C.Y.; Yen, T.J.; Zhang, X. Development and characterization of a silicon-based micro direct methanol fuel cell. Electrochim. Acta, 2004, 49, 821-28.

[3] Yao, S.C.; Tang, X.D.; Hsieh C.C.; Alyousef, Y; Vladimer, M.; Fedder, G.K.; Cristina, H. Micro-electro-mechanical systems (MEMS)-based micro-scale direct methanol fuel cell development. Energy, 2006, 31, 636-49.

[4] Yeom, J.; Jayashree, R.S; Rastogi, C.; Shannon, M.A.; Kenis, P.J.A. Passive direct formic acid microfabricated fuel cells. $J$. Power Sources, 2006, 160, 1058-64.

[5] Shinji, M.; Mohamed, M.; Toshiyuki, M.; Shuichi, S.; Tetsuya, O. MEMS-based design and fabrication of a new concept micro direct methanol fuel cell ( $\mu$-DMFC). Electrochem. Commun., 2004, 6 , $562-65$.

[6] Maynard, H.L.; Meyers, J.P. Miniature fuel cells for portable power: design considerations and challenges. J. Vac. Sci. Technol. $B, \mathbf{2 0 0 2}, 20,1287-97$.

[7] Tanaka, S.; Chang, K.S.; Min, K.B.; Satoh, D.; Yoshida, K.; Esashi, M. MEMS-based components of a miniature fuel cell/fuel reformer system. Chem. Eng. J., 2004, 101, 143-49.
[8] Kelley, S.C.; Deluga, G..A.; Smyrl, W.H. Miniature fuel cells fabricated on silicon substrates. AICHE J, 2002, 48, 1071-1082.

[9] Yu, J.R.; Cheng, P.; Ma, Z.Q.; Yi, B.L. Fabrication of miniature silicon wafer fuel cells with improved performance. J. Power Sources, 2003, 124, 40-46.

[10] Kelley, S.C.; Deluga, G..A.; Smyrl, W.H. A miniature methanol/air polymer electrolyte fuel cell. Electrochem. Solid State, 2000, 3, 407-409.

[11] Heinzel, A.; Hebling, C.; Müller, M.; Zedda, M.; Müller, C. Fuel cells for low power applications. J. Power Sources, 2002, 105, 25055.

[12] Kim, T.; Kwon, S. Catalyst preparation for fabrication of a MEMS fuel reformer. Chem. Eng. J., 2006, 123, 93-102.

[13] Holladay, J.D.; Jones, E.O.; Phelps, M.; Hu, J.L. Microfuel processor for use in a miniature power supply. J. Power Sources, 2002 , 108, 21-27.

[14] Lee, S.J.; Chang-Chien, A.; Cha, S.W.; O' Hayre, R.; Park, Y.I.; Saito, Y.; Prinz, F.B. Design and fabrication of a micro fuel cell array with "flip-flop" interconnection. J. Power Sources, 2002, 112, 410-18.

[15] Yu, J.R.; Cheng, P.; Ma, Z.Q.; Yi, B.L. Fabrication of a miniature twin-fuel-cell on silicon wafer. Electrochim. Acta, 2003, 48, 153741.

[16] Hahn, R.; Wagner, S.; Schmitz, A; Reichl, H. Development of a planar micro fuel cell with thin film and micro patterning technologies. J. Power Sources, 2004, 131, 73-78.

[17] Larminie J.; Dicks, A. Fuel Cell System Explained, 2nd ed.; Wiley $\&$ Sons: New York, 2002 